\title{
A RAPID QUANTITATIVE DYE-BINDING METHOD OF SCREENING GLYCOSAMINOGLYCANS PRESENCE IN MEDICINAL PLANTS
}

\author{
CHE NUR MAZADILLINA ZAHARI, MARINA MOHD SHAM, SAKINA SHAHABUDIN, MOHD-HAIRUL AB RAHIM AND \\ NINA SUHAITY AZMI*
}

Department of Industrial Biotechnology, Faculty of Industrial Sciences and Technology, Universiti Malaysia Pahang, 26300 Kuantan, Pahang, Malaysia. Email: nina@ump.edu.my

Received: 16 October 2018, Revised and Accepted: 29 November 2018

\section{ABSTRACT}

Objectives: The aims of this paper are to extract glycosaminoglycan (GAG) from four local medicinal plants and to characterize the crude extract with highest total sulfated GAG to reduce the dependency of using animals as major sources.

Methods: Crude GAG was extracted from four plants (Gaultheria procumbens, Strobilanthes crispus, Orthosiphon stamineus, and Ficus deltoidea) using hot water extraction with some modifications. Ultraviolet (UV) spectrophotometry was conducted for purity test. Total sulfated GAG was determined using Blyscan assay kit. By comparing results between the extract yields and total sulfated GAG, the plant consisting of high total sulfated GAG was chosen for further characterization. The selected plant sample was examined by microscopy and further analyzed by nuclear magnetic resonance (NMR) and Fourier-transform infrared (FTIR) spectroscopy.

Results: All four plants showed absorbance peaks between 214 and $232 \mathrm{~nm}$ in UV scan that represented negatively charged sugar. 0 . stamineus was found to contain the highest amount of sulfated GAG, $62.63 \pm 0.01 \mu \mathrm{g} / \mathrm{mg}$ by Blyscan assay. Microscopical examination confirmed the identity of O. stamineus sample by comparing to the reference. Both NMR and FTIR analysis of 0 . stamineus crude yield showed the presence of hydroxyl, sulfates, carboxylate, and amine groups, suggesting close resemblances to GAG structure.

Conclusion: The results suggested that all four plants contained GAG compound. 0 . stamineus was found to exhibit the most abundant total sulfated GAG and has the potential to become a new plant-based source for GAG.

Keywords: Blyscan assay, Glycosaminoglycan, Medicinal plants, Orthosiphon stamineus, Plant-based source.

(C) 2019 The Authors. Published by Innovare Academic Sciences Pvt Ltd. This is an open access article under the CC BY license (http://creativecommons. org/licenses/by/4. 0/) DOI: http://dx.doi.org/10.22159/ajpcr.2019.v12i1.30283

\section{INTRODUCTION}

Glycosaminoglycan (GAG) is a type of sugar that widely applied in diverse fields such as cosmetics, supplementary diet, food, and textiles. GAG has five different classes (chondroitin sulfate, heparin, heparan sulfate, dermatan sulfate, and keratan sulfate) and each of them carries specific function that can be recognized from sulfated group presence, except for a unique class known as hyaluronic acid [1-5]. They are negatively charged components belong to polysaccharide group (mucopolysaccharide) and made up of repeating disaccharide units. Consisting of amino sugars, $\mathrm{N}$-acetyl glucosamine, and $\mathrm{N}$-acetyl galactosamine as the repeating units, they are built up along with uronic acid (iduronic acid and glucuronic acid) [6]. In the medicinal area, GAG helps to prevent blood coagulation through biological action carried by heparin that inhibits coagulation process, especially in hemodialysis. GAG is one of the components used to construct dressing to support wound healing [7].

Since GAG is comprehensively utilized worldwide, GAG supply is in constant demand. Porcine is one of the major sources of GAG, but there is a shortage of porcine supply due to its extensive application in other areas as well. Compounds from other animal sources, including marine lives, tend to be easily affected by infectious viruses [3,4]. For example, there is a risk of contracting mad cow disease using cow as a source of GAG [8]. Therefore, using plant source may offer less risk of infections in human.

Since ancient times, local medicinal plants in Malaysia have offered many functional benefits to humans such as wound healing, reducing fever, curing hypertension and diabetes, and treating inflammations. Medicinal plants have become a fundamental source not only in Malaysia but are also utilized by almost 3.4 billion of humankind around the world who depend on natural-based products [9]. Reasonably, medicinal plants can be considered as both safe and effective toward achieving an optimum cure without long-term side effects like those usually resulted by modern drugs $[10,11]$. Considering the awareness of the communities on the importance of these natural treasures, researchers have come out with many studies regarding the functions of natural compounds. Numerous studies have been done on animal extracts since decades, yet there are limited reports on GAG presence in local medicinal plants [12]. In this study, four types of medicinal plants that are known for their benefits in traditional herbalism were chosen and screened for their potential of containing GAG.

Here, the GAG content in plant extracts was quantified using Blyscan assay, a dye-binding method that allows for rapid and accurate quantitative as well as a qualitative measurement for GAG. This assay can determine the total content of sulfated GAG in samples, but not each specific GAG class. On contact with dissociation reagent from Blyscan kit, samples would show calorimetric reaction by giving off darker color, which indirectly represented GAG presence in the samples. Use of Blyscan assay is more simple and convenient to screen for GAG presence in the extracts from medicinal plants. The GAG extract from the selected plant with the most GAG content was characterized using Fourier-transform infrared (FTIR) and nuclear magnetic resonance (NMR). This current study is striving to find a novel plant-based source for GAG that can replace porcine or other animals as sources of GAG. 


\section{METHODS}

\section{Plant material preparation}

Four local medicinal plant samples (Gaultheria procumbens, Strobilanthes crispus, Orthosiphon stamineus, and Ficus deltoidea) were supplied by Delima Jelita Herbs Enterprise situated in Kedah, Malaysia. The plant samples were acquired in the form of the whole plants and came in powdered form.

\section{Hot water extraction}

The extraction method was adapted and modified from two previous studies [13,14]. $20 \mathrm{~g}$ of each sample was dissolved in $400 \mathrm{ml}$ of distilled water. The solutions were mixed at $80-95^{\circ} \mathrm{C}$ for approximately 15-30 min, depending on the texture of the samples. After cooling down, the plant samples were centrifuged at $10,000 \mathrm{rpm}$ for $10 \mathrm{~min}$, and followed by filtration. The residue was discarded while filtrate was collected and kept at $-80^{\circ} \mathrm{C}$ before lyophilization. After freeze-drying, the samples (in powdered form) were concentrated using $70 \%$ ethanol $(\mathrm{v} / \mathrm{v})$. The GAG yield was maintained at a cool and dry place, stored at $4^{\circ} \mathrm{C}$, and its raw powder was kept at room temperature.

\section{Ultraviolet (UV) screening}

About $2 \mathrm{mg}$ of each lyophilized plant sample was diluted in $2 \mathrm{ml}$ of distilled water as a stock solution. Then, about $2 \mu \mathrm{l}$ of the plant's stock solution was diluted into $2 \mathrm{ml}$ of distilled water. During the preparation of the stock solution, the sample was vortexed for a few seconds to make sure the sample blended well before analysis. Solution of $99.9 \%$ methanol was used as a blank and pipetted into a glass cuvette. The cuvette was wiped for a clearer surface to avoid reading interference. The sample aliquots were pipetted into a cuvette and observed under UV spectrophotometer (Shimadzu UV-2600, Kyoto, Japan). The absorbance was read between 200 and $800 \mathrm{~nm}$ and obtained in triplicates.

\section{Blyscan assay}

Blyscan test was conducted using 96-well microplate, with distilled water as a blank. Each $50 \mu \mathrm{l}$ of plant sample was transferred into microcentrifuge tubes and topped up until $100 \mu \mathrm{l}$. Then, $1 \mathrm{ml}$ of Blyscan dye reagent was added into each centrifuge tube and vortexed for $30 \mathrm{~min}$. As an observation, the samples with sulfated GAG may turn into bright pink whereas no change was observed for the absence of GAG. After the samples were centrifuged at 12,000 rpm for $10 \mathrm{~min}$, the supernatant was removed. Approximately $0.5 \mathrm{ml}$ of dissociation agent was added to the samples and vortexed until they mixed thoroughly. To remove foam that formed due to the vigorous vortex, samples were centrifuged for $5 \mathrm{~min}$. An aliquot of $200 \mu \mathrm{l}$ was pipetted into each well of the microplate. The absorbance was read on a microplate reader (Tecan Infinite M200 Pro, Zürich, Switzerland) at $656 \mathrm{~nm}$. A calibration curve was plotted with chondroitin sulfate as a standard.

\section{Microscopy examination}

O. stamineus plant was purchased from Taman Pertanian Jubli Perak Sultan Haji Ahmad Shah, Bandar Indera Mahkota, Kuantan, Malaysia and is maintained at the greenhouse of Kulliyyah of Pharmacy, International Islamic University Malaysia (IIUM) Kuantan. The aerial parts were collected, dried in an oven at $50^{\circ} \mathrm{C}$, powdered and was used as a reference in the microscopical examination of the powdered sample. The various cell structures were determined using methylene blue for general observation, and the starch granules were identified using Lugol's iodine solution. The images were digitally captured with a Leica DM750 microscope (LeicaTM-Wetzlar, Germany) using a video camera plugged to a computer utilizing the Leica Application Suite EZ (LeicaTM-Wetzlar, Germany) software for image analysis. All microscopical pictures were taken with $\times 400$ magnification. The microscopical characters of the powdered form of $O$. stamineus sample were examined under microscopy and compared to the 0 . stamineus reference.

\section{FTIR}

Crude samples were analyzed using FTIR spectrophotometer (Perkin Elmer Spectrum 100, MA, USA). A fraction was taken and ground with potassium bromide powder. To obtain a transparent result for viewing, the fraction must be pressed into pellets before undergoing measurement within the frequency range of $4000-400 \mathrm{~cm}^{-1}$.

\section{NMR}

Approximately $100 \mathrm{mg}$ of crude GAG was dissolved in $0.5 \mathrm{ml}$ of $99.8 \%$ deuterium oxide after microfiltration through $0.45 \mu \mathrm{m}$ nylon filters. Sonification for $60 \mathrm{~s}$ was done to remove air bubbles from the solution. Crude samples were sent to Central Laboratory, Universiti Malaysia Pahang for NMR analysis (Bruker Ultra Shield Plus 500, MA, USA) using supersaturation method and Tetramethylsilane was used as internal reference.

\section{Statistical analysis}

The plant samples were analyzed in triplicates, and the results were reported in mean \pm standard deviation values.

\section{RESULTS}

In this study, GAG was extracted from four medicinal plants by hot water extraction. The initial weight of the whole plant used for the plant extraction was 20 g. Crude GAG was successfully extracted and recorded in Table 1

Purity test of crude extracts was done using UV scan to identify the presence of other compounds than sugar in tested plants. As this study did not proceed to purification step, macromolecule such as protein was expected to be present. Somehow, the macromolecules may not affect the readings of an assay conducted. The UV scan profile (Fig. 1) shows strong absorbance peaks between 200 and $250 \mathrm{~nm}$ and some plants also showed a broad signal around 270-300 nm wavelength. Absorbance peak could be seen in all plants between 214 and $232 \mathrm{~nm}$ that represented negatively charged sugar. One distinct group can be easily identified as carboxylate chromophore between 220 and $230 \mathrm{~nm}$ [15]. A feature in UV scan spectra (around $280 \mathrm{~nm}$ ) of the plants was exhibited by protein presumably linked to the GAG structure. The rest of spectrum was considered as fingerprints.

Total sulfated GAG was determined in Blyscan assay using absorbance values expressed through a calibration curve constructed from chondroitin sulfate standard. Based on the results, all four plants possessed promising GAG content and predominantly proven the ability of the listed plants as GAG sources. Total sulfated GAG content that was reckoned from whole crude GAG for each respective plant extract was shown in Table 2. Out of four tested plants, O. stamineus produced the highest total sulfated GAG from the crude yield.

Since 0 . stamineus emerged with the highest amount of total sulfated GAG, further characterization was performed only on 0 . stamineus. Based on visual observation, the general morphology of the $O$. stamineus plant

Table 1: Crude yield of GAG extracts from four medicinal plants

\begin{tabular}{ll}
\hline Plant samples & GAG yield of extracts (g) \\
\hline Ficus deltoidea & $1.06 \pm 0.02$ \\
Gaultheria procumbens & $4.17 \pm 0.00$ \\
Orthosiphon stamineus & $1.47 \pm 0.00$ \\
Strobilanthes crispus & $0.67 \pm 0.00$ \\
\hline
\end{tabular}

Data are mean \pm SD values; $n=3$. GAG: Glycosaminoglycan, SD: Standard deviation

Table 2: The total sulfated GAG $(\mu \mathrm{g} / \mathrm{mg})$ calculated from their respective crude yield

\begin{tabular}{ll}
\hline Plant samples & Total sulfated GAG in crude yield $(\boldsymbol{\mu g} / \mathbf{m g})$ \\
\hline Ficus deltoidea & $40.61 \pm 0.00$ \\
Gaultheria procumbens & $20.71 \pm 0.00$ \\
Orthosiphon stamineus & $62.63 \pm 0.01$ \\
Strobilanthes crispus & $9.68 \pm 0.01$ \\
\hline Data are mean+SD values; n=3.GAG: Glycosaminoglycan, SD: Standard deviation
\end{tabular}




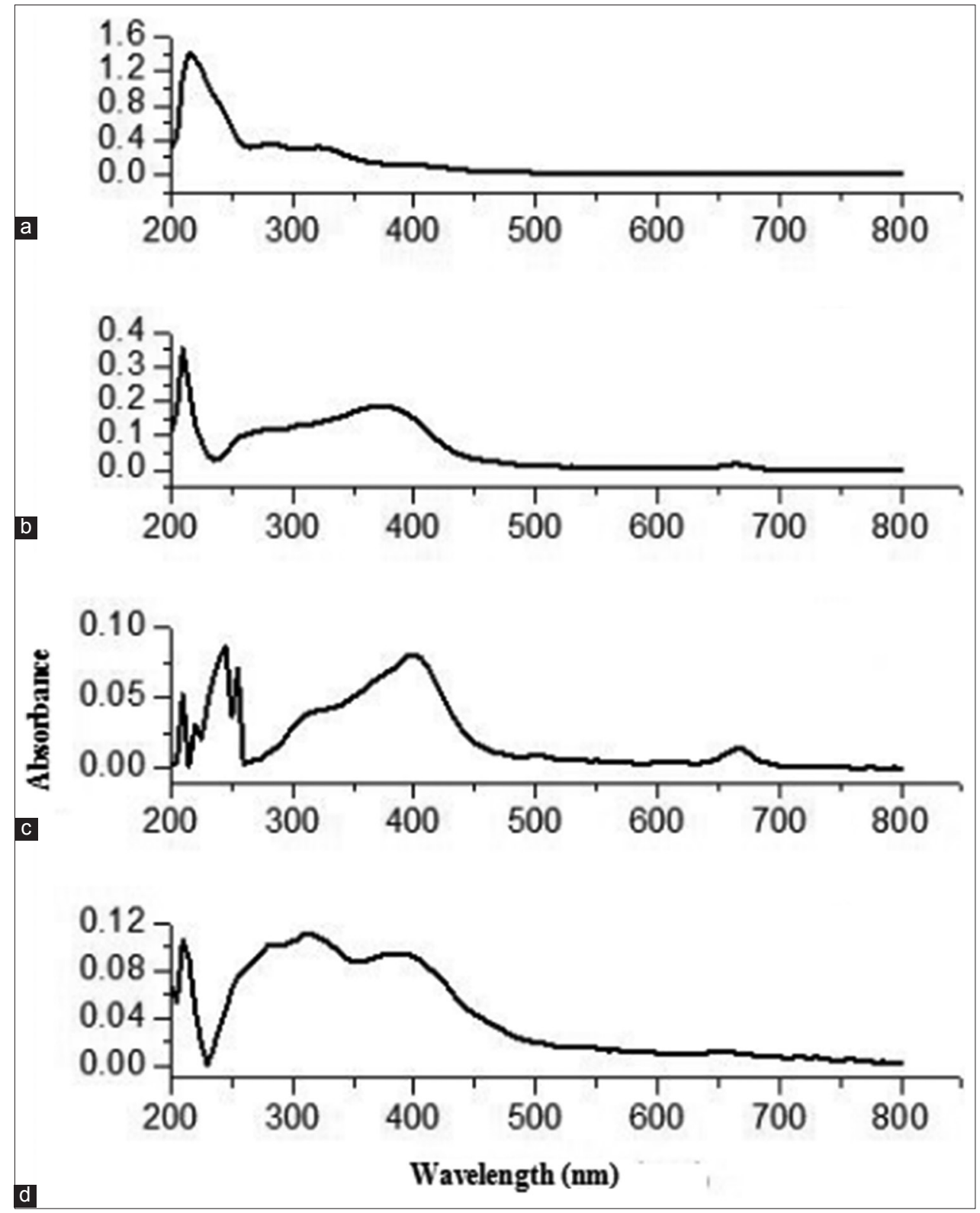

Fig. 1: Ultraviolet spectra of crude glycosaminoglycan extract from (a) Ficus deltoidea, (b) Orthosiphon stamineus, (c) Gaultheria procumbens, and (d) Strobilanthes crispus

was listed. The plant grows multi-branched, with quadrangular stem, and ascending to erect. The leaves are simple, green, with glabrous and a serrate margin, rhomboid shape, and acuminate apex and obtuse base with light green reticulate-pinnate venation (Fig. 2). The bracts, which have short length (1-2 $\mathrm{mm}$ ) with green color, normally hold a cluster of six flowers growing in whorls along the floral axis. The flowers have bell shape, white corolla with long wispy stamens, with an unequal length that measures from $4.7 \mathrm{~cm}$ to $5.2 \mathrm{~cm}$. This appearance makes the flowers seem to be like cat's whiskers and can grow up to $6.2 \mathrm{~mm}$ in length (Fig. 2). It has irregular gamosepalous calyx and corolla lobes, which covered with minute white hairs. Each flower has four stamens that are inserted near the base of the corolla tube. The fruit pod contains four oval-shaped seeds with hard external coat and rough surface [16].

For the authentication of $O$. stamineus, the microscopical characters of the powdered form of $O$. stamineus sample were examined and compared to the 0 . stamineus reference (Fig. 3). The same microscopical characters that include sinuous epidermal cells, diacytic stomata, parenchymal cells, uniseriate trichomes, tracheids, starch granules, and fragments of vessels with spiral and reticulate thickening were observed in both powdered sample and $O$. stamineus reference. Therefore, the powdered sample was authenticated as 0 . stamineus.

The 0 . stamineus crude extract was further characterized by FTIR. Characteristics peaks of $O$. stamineus at a wavelength of $4000-400 \mathrm{~cm}^{-1}$ are presented (Fig. 4). Crude GAG present in 0 . stamineus showed bands between $1540 \mathrm{~cm}^{-1}$ and $1500 \mathrm{~cm}^{-1}$, suggesting protein residual [13]. The spectrum in the $3413-3250 \mathrm{~cm}^{-1}$ region was originated from hydroxyl group $(\mathrm{O}-\mathrm{H})$, such as those that can be found in glucuronic acid [17]. Stretching vibrations of $\mathrm{S}=0$ for sulfates $\left({ }^{-} \mathrm{SO}_{3}\right)$ were detected at several spectra in the range of $1312-1260 \mathrm{~cm}^{-1}$ from the crude sample, similar to the standard that is identical to GAG's characteristics [18]. A single peak was recorded between 1739 and $1700 \mathrm{~cm}^{-1}$, suggesting carboxylate (-COO-)bond [19]. O. stamineus crude yield also showed clear peaks in the $1300-1000 \mathrm{~cm}^{-1}$ region, indicating amine (C-N) bond. Meanwhile, the spectrum between 2928 and $2800 \mathrm{~cm}^{-1}$ indicates the stretching of carbon-hydrogen bond that creates the skeleton of GAG compound. 


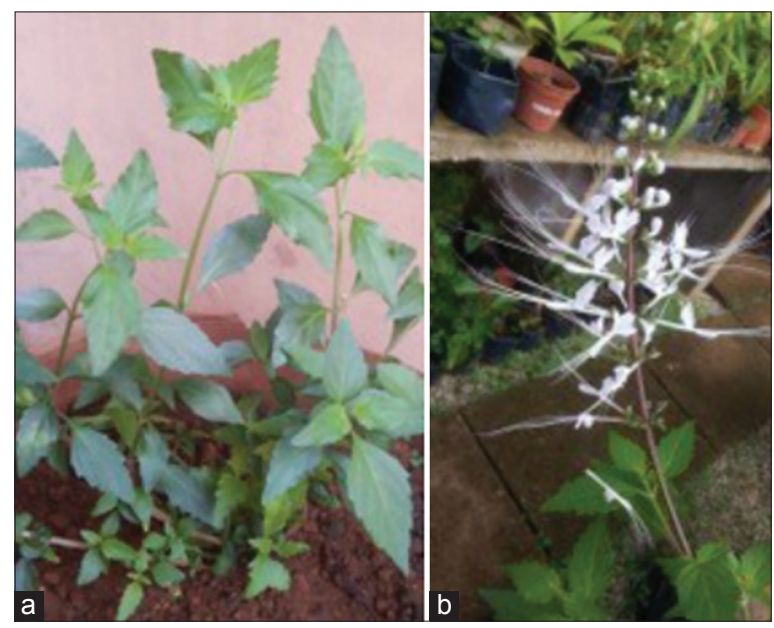

Fig. 2: General morphology of the leaves and inflorescence of Orthosiphon stamineus plant (a) the leaves and (b) the inflorescence
The GAG in 0 . stamineus crude extract was also characterized in NMR. The ${ }^{1} \mathrm{H}$ NMR analysis confirmed H-4, H-5 of glucuronic acid (Glcp-UA) residue between 3.20 and 3.61 ppm (Fig. 5). This region is also comprised H-6 of N-acetyl galactosamine (Galp-Nac) residue. The signal at 1.91-1.96 ppm region suggested N-acetyl methyl of GalpNAc residue while signal at $4.29-4.78 \mathrm{ppm}$ verified the presence of H-4 and glucuronic group [20]. There was no unusual peak detected at $3.50 \mathrm{ppm}$ that may indicate contaminant within sample [20]. Based on the existing peaks, some spectra showed signals for hyaluronic acid that ranges from 2.64 to $4.78 \mathrm{ppm}$ which resembles protons on sugar ring. The spectra also showed the presence of heparin through 2.14-2.16 ppm signals. It can be speculated that the sample has a close resemblance to GAG compound.

\section{DISCUSSION}

This study chose to employ hot water extraction method because hot water can break plants' cell wall to bring out GAG effectively. A study on polysaccharide extraction out of Chinese herbs also applied hot water as their main solvent [21]. Other studies also reviewed that hot water extraction is significantly employed in the pharmaceutical sector, which

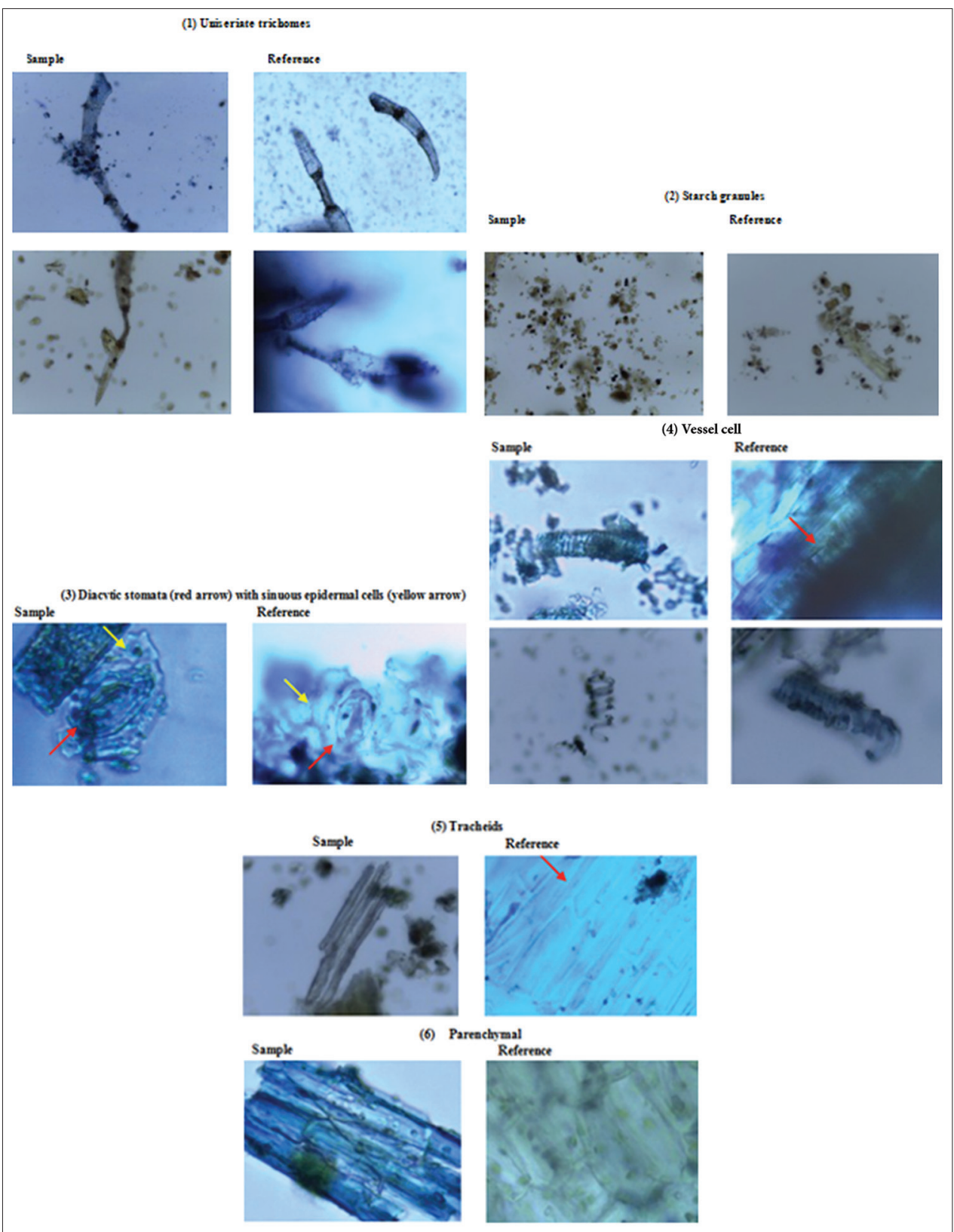

Fig. 3: Comparison of microscopical characters of Orthosiphon stamineus powdered form and the reference sample 
meets this current study's scope $[10,22]$. Hot water extraction would be a better choice in industrial applications for human consumption. One study compared ethanol extraction and hot water extraction, in which the respective extract yields were further tested on mice for its survival effect on influenza A/PR/8/34 [23]. Hot water extracts showed a remarkable effect on mice survival and also on its defense ability compared to ethanol extract [23]. In addition, hot water extraction was used to elicit anticoagulant effect (one of the medical properties caused by GAG compound) in selected medicinal plants in South Africa [24]. Hot water is the most familiar extraction method especially in dealing with a bioactive compound study [25].

There are numerous ways to quantify total sulfated GAG in samples, including spectrophotometric assays. Most of these assays work by detecting sulfation level based on the changes of absorption spectrum on specific dyes [26]. For example, 1,9-dimethylmethylene blue (DMMB) assay that is shown to be effective for both animal and plant samples $[12,27]$. Alas, this assay has drawbacks in term of its stability and easily affected by some interferences such as protein residue [26]. Other spectrophotometric assays may use Alcian blue dye that works in the same principle as DMMB but involves more tedious and time-

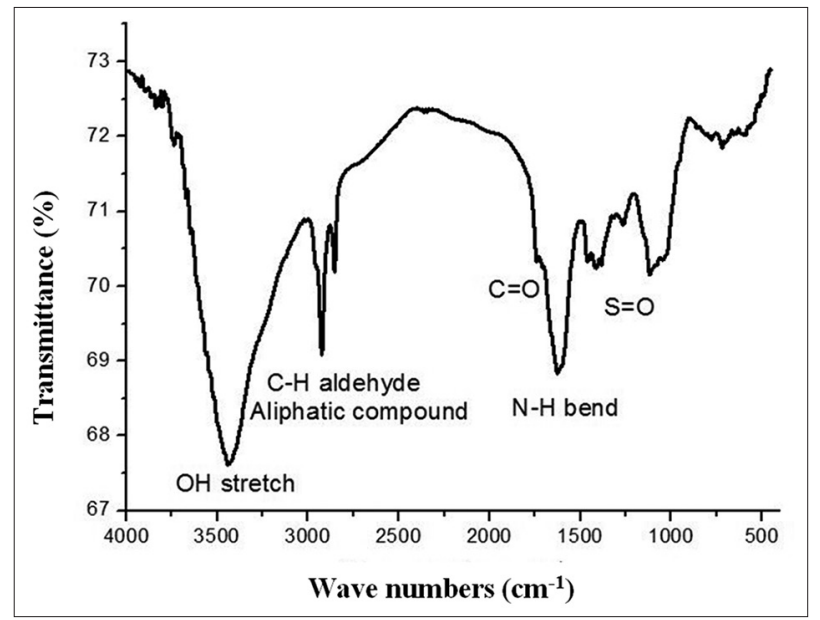

Fig. 4: Fourier-transform infrared spectra of crude glycosaminoglycan extracted from Orthosiphon stamineus consuming protocol [28]. Thus, the current study chose to employ Blyscan assay with simpler and more conventional procedures. Blyscan assay has been used for all types of sample, for instance, quantification of GAG amount in nanofibrous and cell pellet [29]. Another study determined chondroitin sulfate out of synovial fluid by Blyscan assay [30]. In addition, a cancer study on mice discussed about sulfated GAG present in mice could be detected by specific binding of cationic dye in Blyscan assay toward sample [31]. These previous studies justified the application of Blyscan assay for GAG determination in the current study.

Here, O. stamineus was shown to contain the highest total sulfated GAG as compared to other three plants. From the previous study that investigated extraction and quantification of GAG from Acanthaster planci starfish, the highest GAG amount was found in starfish's body coelomic fluid at $55.79 \pm 0.65 \mu \mathrm{g} / \mathrm{mg}$ [32]. By comparison with A. planci, O. stamineus has potential to give much higher GAG amount. Another research that studied about one of the GAG classes, heparin, from seaweed showed that seaweed contained $2.3 \mathrm{mg} / 50 \mathrm{~g}$ of sulfated GAG, in which seaweed exhibited lower value when compared with $S$. crispus in this current study [33]. Overall, these two sources of GAG (seaweed and starfish) showed relatively smaller values of GAG than $O$. stamineus. Even though $G$. procumbens yielded about 3 times higher crude GAG extracts than $O$. stamineus, somehow, the latter plant exhibited much higher total sulfated GAG from its crude yield than G. procumbens. The reason for this could be possibly due to the chemical constituents that are present in the respective medicinal plants.

Cell proliferation is one of the abilities possessed by all four medicinal plants tested in the current study. It can be seen though the properties such as anticancer, anticoagulant, antioxidant, anti-inflammatory, and wound healing. G. procumbens, also known as Sambung Nyawa in Malay language (meaning of "prolongation of life"), is commonly consumed raw or used in cooking for its beneficial medicinal properties. This plant has been shown to have cytotoxic activity on cancer cells [34]. F. deltoidea, or Tabat Barito, has been traditionally made as a treatment for diabetes mellitus in regulating blood sugars. Studies were done on $F$. deltoidea for the presence of antidiabetic, antioxidant, and antihyperglycemic properties [35,36]. F. deltoidea also contains chlorintype alkaloid compound that can inhibit breast tumor MCF-7 cells [37]. S. crispus, or Pecah Beling, shows antidiabetic properties when tested in hyperglycemic rats [38].

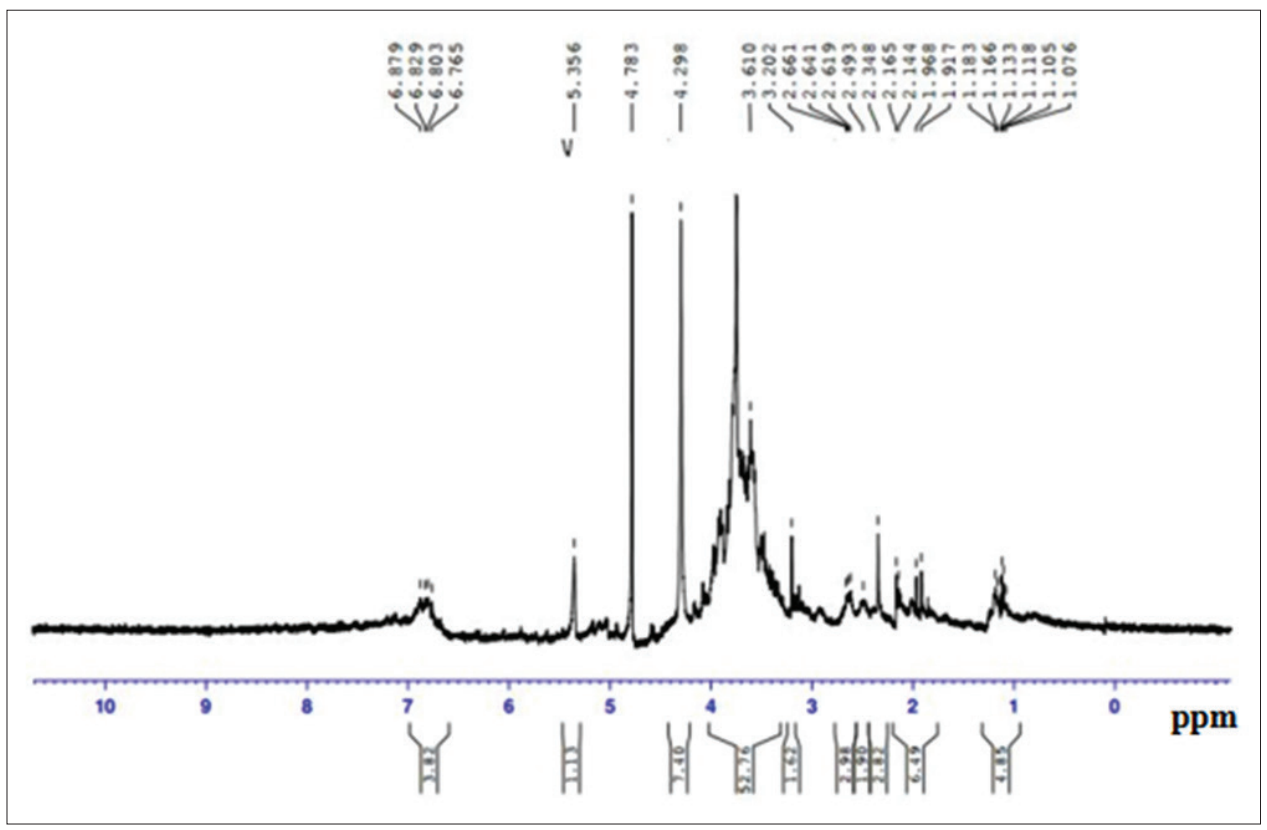

Fig. 5: Nuclear magnetic resonance spectra that correspond to disaccharide sequences of crude glycosaminoglycan extracted from Orthosiphon stamineus 
Meanwhile, O. stamineus, or Cat's Whiskers, could trigger diuretic and uricosuric actions when treated in rats [39]. Leaf extracts of $O$. stamineus displayed weak inhibition of biofilm formation of Staphylococcus aureus [40]. One of the main constituents in the 0 . stamineus plant leaf extracts, namely polyphenols, contributes to its antioxidant potential [41,42]. O. stamineus also possesses active components such as terpenoids [43]. The polyphenols, which are mainly based on the plant's leaves, contribute the most in the active biological activity in 0 . stamineus [44]. Thus, the secondary metabolites compounds in $O$. stamineus such as terpenes are responsible to induce the plant's capability as anti-inflammatory and antioxidant, as well as promote cell proliferation [45]. Based on a phytochemical study, O. stamineus contains many other compounds such as saponins, organic acids, chromeno, and myo-inositol [46]. Further phytochemical studies on these medicinal plants may reveal more of their therapeutic benefits.

In the characterization of the plant samples, UV scanning is necessary for rough identification of the compounds that exist in the samples. UV scanning can be conducted to determine sample purity [15]. This spectroscopy can also help to distinguish GAG compounds from other sugar types. This current study applied water extraction technique, so the same solvent was used as the blank and for sample dilution. Other than ethanol, hexane or cyclohexane, it is important to avoid using other solvents with double or triple bonds that may interfere absorbance readings due to their molar concentrations. Although noises were expected to appear in the UV spectra since the crude GAG extracts were not purified in this study, their presence did not interfere the analysis.

Characterization by FTIR analysis confirmed the identity of $O$. stamineus crude extract as an aliphatic compound due to the presence of spectrums below $3000 \mathrm{~cm}^{-1}$ wavenumbers. FTIR can be used to identify the organic functional groups contained in the crude extract, allowing for rapid and reliable detection in diverse sample types $[17,47]$. The O. stamineus crude extract showed several absorbance peaks that indicate amine, carboxyl, hydroxyl, carbonyl, and sulfate groups. Even though some protein residual was detected, they did not cause interference in assays conducted. The presence of protein residual could be attributed to the fact that the 0 . stamineus extract had not been purified and was still in crude form. Subsequently, NMR was conducted to determine the skeleton of compounds found in the $O$. stamineus plant. NMR is a suitable instrument in providing chemical composition as well as the structure of biological systems [13]. The NMR analysis showed the ranges of peaks representing functional groups that are present in a GAG structure, suggesting that crude compound extracted from 0 . stamineus are potentially GAG. Close similarity of the signals exhibited during characterizations using FTIR and NMR could be seen. These results supported the evidence that the crude extracts from $O$. stamineus were indeed GAG. Thus, this study chose 0 . stamineus as the best plant for its promising amount of sulfated GAG.

\section{CONCLUSION}

The GAG was isolated from four types of local medicinal plants. Within this study, polysaccharides were extracted using hot water extraction while the amount of GAG was reckoned from the mechanism of dye present in Blyscan kit and analyzed through a calibration curve. O. stamineus plant produced the highest amount of sulfated GAG from an aliquot taken compared to other three medicinal plants. Based on FTIR and NMR analysis, the 0 . stamineus crude yield showed resemblances to GAG structure with absorbance at regions indicating the presence of hydroxyl, sulfates, carboxylate, and amine groups. The tremendous amounts of GAG that could be extracted from medicinal plants showed huge potential of becoming a successful source of GAG and subsequently can replace animal sources.

\section{ACKNOWLEDGMENT}

The authors would like to gratefully acknowledge Universiti Malaysia Pahang for operation research grants (UMP-RDU130308 and UMP-RDU180304), Ministry of Higher Education for Research
Acculturation Grant Scheme (RAGS RDU 131406), and Fundamental Research Grant (FRGS RDU 140131). The authors are also thankful to Dr. Norazian Mohd Hassan of Kuliyyah of Pharmacy, IIUM Kuantan, and to Dr. Shamsul Khamis of the Institute of Bioscience, University Putra Malaysia, for their contribution in microscopical examination and identification of $O$. stamineus sample, respetively.

\section{AUTHORS' CONTRIBUTION}

CNMZ performed extraction, GAG quantification, characterization by NMR and FTIR, data interpretation, and wrote the manuscript. SS contributed for interpretation of the data and manuscript preparation. MSM and MHAR contributed for plant extraction. NSA supervised the laboratory work, initiated for research design, and proofread the manuscript.

\section{CONFLICTS OF INTEREST}

The authors hereby declare that no conflicts of interest are involved that might influence the results and/or discussion reported in this manuscript.

\section{REFERENCES}

1. Sham MM, Azmi NS, Ab Rahim MH. Review: Glycosaminoglycans (GAGs) versus cancer. J Environ Bioremediat Toxicol 2014;2:58-61.

2. Zahari CN, Azmi NS. Halal source of medication: Glycosaminoglycan derived medicinal plant. Int J Appl Chem 2016;12:803-10.

3. Azmi NS, Fernig DG. Heparan Sulfate Surfaces to Probe the Functions of the Master Regulator of the Extracellular Space. Handbook of Biofunctional Surfaces. Singapore: Pan Stanford Publishing; 2013. p. 591-616.

4. Idrus NH, Azmi NS, Palliah JV. Waste to wealth: Alternative source of glycosaminoglycans (GAGs) from sea food waste. IIOAB J 2016;7 Suppl 1:543-7.

5. Sham MM, Azmi NS. Blue-spotted stingray: A promising source of beneficial glycosaminoglycans (GAGs). Int J Appl Chem 2016;12:795-802.

6. Lokwani R, Azmi NS, Yusoff MM, Ichwan SJ. Beyond anticoagulant: Heparin as a potential anti-cancer agent. J Biochem Microbiol Biotechnol 2014;2:76-82.

7. Toppo FA, Pawar RS. Novel drug delivery strategies and approaches for wound healing managements. J Crit Rev 2015;2:12-20.

8. Cesaretti, M, Luppi E, Maccari F, Volpi N. Isolation and characterization of a heparin with high anticoagulant activity from the clam Tapes phylippinarum: Evidence for the presence of a high content of antithrombin III binding site. Glycobiology 2004;14:1275-84.

9. Doughari JH. Phytochemicals: Extraction Methods, Basic Structures and Mode of Action as Potential Chemotherapeutic Agents. Phytochemicals-A Global Perspective of Their Role in Nutrition and Health. Croatia: INTECH Open Access Publisher; 2012. p. 1-32.

10. Azmir J, Zaidul IS, Rahman MM, Sharif KM, Mohamed A, Sahena F, et al. Techniques for extraction of bioactive compounds from plant materials: A review. J Food Eng 2013;117:426-36.

11. Azwanida NN. A review on the extraction methods use in medicinal plants, principle, strength and limitation. Med Aromat Plants 2015;4:196.

12. Choocheep K, Saenkham C, Borwornchaiyarit S, Chaiisaraseree K, Chimchai J, Moonpa T. Investigation of sulfated glycosaminoglycans and their agarose gel electrophoresis patterns from plants extracts. J Assoc Med Sci 2018;51:11-8.

13. Manjusha KP, Saleena M. Isolation and Characterization of Glycosaminoglycans and A Study of Its Bioactive Potential in Two Commercially Important Species of Cephalopods, Loligo duvauceli and Sepia pharaonis. A Thesis. Kochi: Cochin University of Science and Technology; 2011.

14. Movahedi A, Basir R, Rahmat A, Charaffedine M, Othman F. Orthosiphon stamineus: An Asian tea with substantial anticancer properties. J Nutr Sci Diet 2015;1:44-52.

15. Lima MA, Rudd TR, de Farias EH, Ebner LF, Gesteira TF, de Souza LM, et al. A new approach for heparin standardization: Combination of scanning UV spectroscopy, nuclear magnetic resonance and principal component analysis. PLoS One 2011;6:e15970.

16. Keng CK, Siong LP. Morphological similarities and differences between the two varieties of cat's whiskers (Orthosiphon stamineus 
Benth.) grown in Malaysia. Int J Bot 2006;2:1-6.

17. Longas MO, Cheairs K, Puchalski MM, Park JI. Reliability of Fourier transform infrared spectroscopy in the characterization of human skin. Adv Biol Chem 2011;1:24-8.

18. Vidhyanandhini R, Saravanan R, Vairamani S, Shanmugam A. The anticoagulant activity and structural characterization of fractionated and purified glycosaminoglycans from venerid clam Meretrix casta (Chemnitz). J Liq Chromatogr Related Technol 2014;37:917-29

19. Cael JJ, Isaac DH, Blackwell J, Koenig JL. Polarized infrared spectra of crystalline glycosaminoglycans. Carbohydr Res 1976;50:169-79.

20. DeAngelis PL, Gunay NS, Toida T, Mao WJ, Linhardt RJ. Identification of the capsular polysaccharides of Type D and F Pasteurella multocida as unmodified heparin and chondroitin, respectively. Carbohydr Res 2002;337:1547-52.

21. Guan D, Zhang Z, Yang Y, Xing G, Liu J. Immunomodulatory activity of polysaccharide from the roots of Actinidia Kolomikta on macrophages. Int J Biol 2011:3:3-10

22. Widyaningsih TD, Rukmi WD, Sofia E, Wijayanti SD, Wijayanti N, Ersalia R, et al. Extraction of glycosaminoglycans containing glucosamine and chondroitin sulfate from chicken claw cartilage. Res J Life Sci 2017;3:181-9.

23. Singh N. A Comparison of Both Water and Ethanol Extracts Prepared from Echinacea purpurea and Echinacea angustifolia on the Response to Influenza A/PR/8/34 Infection in Mice. A Thesis. Ames, IA: Iowa State University; 2010.

24. Kee NL, Mnonopi N, Davids H, Naudé RJ, Frost CL. Antithrombotic/ anticoagulant and anticancer activities of selected medicinal plants from South Africa. Afr J Biotechnol 2008;7:217-23.

25. Vergara-Salinas JR, Bulnes P, Zúñiga MC, Pérez-Jiménez J, Torres JL, Mateos-Martín ML, et al. Effect of pressurized hot water extraction on antioxidants from grape pomace before and after enological fermentation. J Agric Food Chem 2013;61:6929-36.

26. Barbosa I, Garcia S, Barbier-Chassefière V, Caruelle JP, Martelly I, Papy-García D, et al. Improved and simple micro assay for sulfated glycosaminoglycans quantification in biological extracts and its use in skin and muscle tissue studies. Glycobiology 2003;13:647-53.

27. de Jong JG, Wevers RA, Laarakkers C, Poorthuis BJ. Dimethylmethylene blue-based spectrophotometry of glycosaminoglycans in untreated urine: A rapid screening procedure for mucopolysaccharidoses. Clin Chem 1989;35:1472-7

28. Linharattanaruksa P, Srisuwatanasagul S, Ponglowhapan S, Khalid M, Chatdarong K. Collagen and glycosaminoglycan profiles in the canine cervix during different stages of the estrous cycle and in open- and closed-cervix pyometra. J Vet Med Sci 2014;76:197-203.

29. Li WJ, Tuli R, Okafor C, Derfoul A, Danielson KG, Hall DJ, et al. A three-dimensional nanofibrous scaffold for cartilage tissue engineering using human mesenchymal stem cells. Biomaterials 2005;26:599-609.

30. Brown MP, Trumble TN, Sandy JD, Merritt KA. A simplified method of determining synovial fluid chondroitin sulfate chain length. Osteoarthritis Cartilage 2007:15:1443-5.

31. Davies Cde L, Berk DA, Pluen A, Jain RK. Comparison of igG diffusion and extracellular matrix composition in rhabdomyosarcomas grown in mice versus in vitro as spheroids reveals the role of host stromal cells.
Br J Cancer 2002;86:1639-44.

32. Bahrom NA, Sirajudeen K, Yip GW, Latiff AA, Ghazali FC. Sulfated glycosaminoglycans from crown-of-thorns Acanthaster planciextraction and quantification analysis. Food Sci Nutr 2013;1:83-9.

33. Ganesh EA, Das S, Arun G, Balamurugan S, Raj RR. Heparin like compound from green alga Chaetomorpha antennina-as potential anticoagulant agent. Asian J Med Sci 2009;1:114-6.

34. Tan HL, Chan KG, Pusparajah P, Lee LH, Goh BH. Gynura procumbens: An overview of the biological activities. Front Pharmacol 2016;7:52.

35. Adam Z, Hamid M, Ismail A, Khamis, S. Effect of Ficus deltoidea aqueous extract on blood glucose level in normal and mild diabetic rats. Malaysian J Health Sci 2007;5:9-16.

36. Misbah H, Aziz AA, Aminudin N. Antidiabetic and antioxidant properties of Ficus deltoidea fruit extracts and fractions. BMC Complement Altern Med 2013;13:118.

37. Murni A, Hanif N, Kita M, Darusman LK. Methyl 10-epi-pheophorbide A from MCF-7 cells active layer of the Indonesian Ficus deltoidea Jack leaves. Int J Pharm Pharm Sci 2017;9:183-6.

38. Fadzelly AB, Asmah R, Fauziah O. Effects of Strobilanthes crispus tea aqueous extracts on glucose and lipid profile in normal and streptozotocin-induced hyperglycemic rats. Plant Foods Hum Nutr 2006;61:7-12

39. Olah NK, Radu L, Mogoşan C, Hanganu D, Gocan S. Phytochemical and pharmacological studies on Orthosiphon stamineus Benth. (Lamiaceae) hydroalcoholic extracts. J Pharm Biomed Anal 2003;33:117-23.

40. Pratiwi SU, Lagendijk EL, Hertiani T, Weert SD, Cornellius AM, Hondel JJ. Antimicrobial effects of Indonesian medicinal plants extracts on planktonic and biofilm growth of Pseudomonas aeruginosa and Staphylococcus aureus. Int J Pharm Pharm Sci 2015;7:183-91.

41. Akowuah G, Ismail Z, Norhayati I, Sadikun A. The effects of different extraction solvents of varying polarities on polyphenols of Orthosiphon stamineus and evaluation of the free radical-scavenging activity. Food Chem 2005;93:311-7.

42. Pan Y, Abd-Rashid BA, Ismail Z, Ismail R, Mak JW, Pook PC, et al. In vitro modulatory effects of Andrographis paniculata, Centella asiatica and Orthosiphon stamineus on cytochrome P450 2C19 (CYP2C19). J Ethnopharmacol 2011;133:881-7.

43. Yam MF, Ang LF, Basir R, Salman IM, Ameer OZ, Asmawi MZ, et al. Evaluation of the anti-pyretic potential of Orthosiphon stamineus benth standardized extract. Inflammopharmacology 2009;17:50-4.

44. Yam MF, Lim V, Salman IM, Ameer OZ, Ang LF, Rosidah N, et al. HPLC and anti-inflammatory studies of the flavonoid rich chloroform extract fraction of Orthosiphon stamineus leaves. Molecules 2010;15:4452-66.

45. Kato-Noguchi H, Hamada N, Morita M, Suenaga K. A novel allelopathic substance, 13-epi-orthosiphol $\mathrm{N}$, in Orthosiphon stamineus. J Plant Physiol 2013;170:1-5.

46. Takeda Y, Matsumoto T, Terao H, Shingu T, Futatsuishi Y, Nohara, T, et al. Orthosiphol D and E, minor diterpenes from Orthosiphon stamineus. Phytochemistry 1993;33:411-5.

47. Naumann D, Helm D, Labischinski H. Microbiological characterizations by FT-IR spectroscopy. Nature 1991;351:81-2. 